\title{
Avaliação escolar: uma contribuição sócio-histórica para o estudo da atribuição de notas
}

School evaluation: a socio-historical contribution to the study of grade assignment

Evaluación escolar: una contribución sociohistórica al estudio de la asignación de notas

\author{
Natália de Lacerda Gil \\ Universidade Federal do Rio Grande do Sul (Brasil) \\ http://lattes.cnpq.br/8340007478393697 \\ https://orcid.org/0000-0002-0818-4858 \\ natalia.gil@uol.com.br
}

\section{Resumo}

A atribuição de notas ou conceitos aos alunos é prática cotidiana nas escolas, embora tenhamos muito pouco conhecimento sobre os critérios efetivamente mobilizados pelos professores nesses processos e conheçamos ainda pouco acerca da história desse aspecto da cultura escolar. Assim, no presente trabalho busco contribuir com a história da avaliação principalmente do ponto de vista teórico, focalizando, em diálogo com estudos sociológicos, a dimensão classificatória envolta na escala de excelência escolar que a atribuição de notas permite formular. A fim de exemplificar a potencialidade do exame de fontes constituídas a partir da escrituração escolar, apresento a análise de fichas de notas de uma escola católica de Porto Alegre entre 1957 e 1964. Articulando-se a estudos já desenvolvidos sobre o tema na História da Educação, neste trabalho explicito o detalhamento e a busca de precisão e objetividade perceptíveis na quantificação dos desempenhos escolares e no debate pedagógico acerca da questão.

Palavras-chave: História da avaliação. Excelência escolar. Cultura escolar. 


\begin{abstract}
Students evaluation and assessment is a daily practice in schools, although we have very little knowledge indeed on the criteria mobilized by teachers in those processes and we know not much concerning the history of that aspect of the school culture. In this paper, I intend to contribute with the history of evaluation, mainly on a theoretical perspective, in dialogue with sociological studies, by focusing a classificatory practice presents in the scale of excellence that giving grades allows to formulate. Besides, in order to exemplify the potentiality of the examination of sources constituted from the school scripture, I analyse records of grades of a Catholic school located in Porto Alegre (Brazil) covering the period 1957-1964. In articulation with others historical studies, I explicit the search of precision and objectivity in the quantification of the school outcomes and the pedagogic debate concerning the subject.
\end{abstract}

Key words: History of evaluation. School excellence. School culture.

\title{
Resumen
}

La atribución de notas para los estudiantes es una práctica diaria en las escuelas, aunque tenemos muy pocos conocimientos efectivamente sobre los criterios movilizados por los profesores en esos procesos y sepamos todavía poco con respecto a la historia de ese aspecto de la cultura escolar. Así, en este trabajo busco aportar contribuciones a la historia de la evaluación, principalmente de un punto de vista teórico, enfocando, en dialogo con estudios sociológicos, la dimensión clasificatoria envuelta en la escala de excelencia que la atribución de notas permite formular. Por otro lado, con el fin de ejemplificar la posibilidad del examen de fuentes constituidas a partir de la escritura escolar, traigo el análisis de registros de notas de una escuela católica de Porto Alegre entre 1957 y 1964. En articulación con estudios ya desarrollados en Historia de la Educación, explicito la búsqueda de precisión y objetividad perceptible en la cuantificación del rendimiento de la escuela y en el debate pedagógico con respecto al tema.

Palabras claves: Historia de la evaluación. Excelencia escolar. Cultura escolar. 
No último dia dos exames finais nós todos ficáramos em pé atrás dos nossos bancos, as boinas na cabeça, como se estivéssemos em posição de sentido. O senhor Cortês caminhou de um para o outro com passos graves, anunciou a nota final com sua expressão habitualmente severa e nos entregou o boletim com olhar fixo. Sem alegria, pálido, o meu vizinho de banco, bom aluno, recebeu o dele e o segurou nas mãos como se fosse uma Bíblia. Rindo, o pior aluno, o preferido das meninas, bronzeado de sol, deixou cair o seu no chão, como se fosse lixo. Em seguida, voltamos para o calor de um dia de julho.

Pascal Mercier (2013)

Os sistemas de ensino organizam-se cada vez mais recorrendo a processos avaliativos. De um lado, tem-se a intenção de quantificar o rendimento do ensino, produzindo índices de aprovação/reprovação e de evasão por exemplo, de outro, tem-se a necessidade de conhecer e precisar as aprendizagens dos alunos. A convicção, amplamente difundida, na objetividade dos procedimentos de quantificação dos desempenhos, associada às demandas atuais de accountability podem, eventualmente, levar a considerar apenas os instrumentos e os resultados, notadamente nas análises de políticas educacionais, dando pouca atenção aos processos sócio-históricos de constituição de tais práticas que criaram, é forçoso notar, também as condições de sua legitimação. As avaliações escolares são práticas culturais cuja história nos permite compreender as lógicas que estruturam a escola na Modernidade. Nesse sentido, neste trabalho assumo as avaliações escolares e especificamente a prática de atribuição de notas como objeto de investigação que merece atenção. A intenção está em pontuar a relevância da temática no campo da História da Educação e apresentar, como exemplo da potencialidade do exame desse tipo de fonte, a análise de um conjunto de 531 fichas de notas de uma escola católica de Porto Alegre, compreendendo o período de 1957 e 1964. O texto se inicia com uma breve incursão por questões colocadas à historiografia da educação relativas à avaliação como objeto e à escrituração escolar como fonte. Em seguida, proponho o diálogo com algumas teorizações sociológicas acerca da excelência escolar e o caráter classificatório das avaliações procedidas nas escolas. Faço, também, considerações sobre a demanda por quantificação dos desempenhos dos alunos como critério para imprimir maior objetividade e eficiência ao ensino. Por fim, apresento uma breve descrição e algumas análises da documentação assumida como fonte.

\section{História da avaliação e a escrituração escolar como fonte}

A avaliação escolar não é tema novo na educação. Desde a constituição da escola moderna, a partir do século XVI, a avaliação faz parte das práticas que caracterizam essa instituição. Franco Cambi (1999) ressalta que o mundo moderno se estrutura em torno de processos de civilização, racionalização e institucionalização que passam a organizar a vida social. Dentre outros aspectos, tem-se a afirmação "de uma ética da responsabilidade, em relação à da convicção (ideal e ideológica), que elabora um cálculo dos custos e dos benefícios de uma ação, que indaga sobre sua produtividade e eficácia” (CAMBI, 1999, p. 200). Além disso, há 
a dimensão da institucionalização, do minucioso controle social, articulado no tecido da sociedade, exercido por meio de instituições ad hoc e que diz respeito à classificação dos indivíduos e dos comportamentos, à criação de tipologias sociais diferenciadas (os loucos, os criminosos, os doentes, os pobres, os órfãos etc.) que são estudadas e dirigidas em vista ou de uma integração produtiva na sociedade ou de uma separação desta, para tornálas inofensivas (CAMBI, 1999, p. 200-201).

A avaliação realizada na escola moderna articula-se a esse conjunto de elementos tendo, portanto, desde aquele momento o caráter de exame e a intenção de permitir situar cada indivíduo no quadrante onde pudesse melhor produzir (FOUCAULT, 1987).

Recentemente, desde o século XX, o debate pedagógico vem pautando a avaliação como um dos temas centrais da Didática e tem-se questionado a pertinência de seu caráter de exame no âmbito de uma escola que se torna progressivamente acessível a todos e que, efetivamente, se estabelece, no caso brasileiro, como direito de todos. Nesse sentido, o que os debates sublinham é a incoerência da manutenção de uma prática seletiva e excludente em uma instituição que deveria incluir e garantir a permanência de todos. A propósito Luckesi (2002, p. 84) aponta nas ações dos professores o "equívoco em denominar de 'avaliação', quando o que se faz é praticar "exames"”. Segundo ele,

avaliar é o ato de diagnosticar uma experiência, tendo em vista reorientá-la para produzir o melhor resultado possível; por isso, não é classificatória nem seletiva; ao contrário, é diagnóstica e inclusiva. $\mathrm{O}$ ato de examinar, por outro lado, é classificatório e seletivo e, por isso mesmo, excludente, já que não se destina à construção do melhor resultado possível; tem a ver, sim, com a classificação estática do que é examinado (LUCKESI, 2002, p. 84).

A seletividade escolar, engendrada pelas práticas avaliativas presentes na escola brasileira, só se tornará questão a ser discutida a partir dos anos 1960, quando maior número de alunos começa a buscar o ensino superior (GATTI, 2002). Apesar das contradições de uma escola seletiva que se apresenta como democrática estarem presentes durante todo o século XX - e ainda hoje -, é apenas na segunda metade do século que a questão passa a ter uma discussão mais ampliada. Bernadete Gatti (2002, p. 18) alerta:

Note-se que, nos anos 60 e início dos 70, ainda não se discutem a reprovação escolar em massa que se processava no ensino fundamental e a evasão de alunos, que tinha foros dramáticos. Nas escolas, fazer alunos "repetirem" o ano, por "avaliações rigorosas", tornou-se "natural". O fato de se eliminarem alunos das escolas, especialmente os de baixa renda, pelo insucesso ininterrupto, não era questionado.

Apesar da relevância da temática, Denice Catani $(2017$, p. 9) afirma que

os estudos da história das práticas de avaliação na educação brasileira não são abundantes embora as linhas gerais de tais práticas tenham sido já estabelecidas e nos permitam reconhecer que suas variações associaram-se, desde a primeira metade do século $\mathrm{XX}$ a essa incorporação de justificativas científicas psicológicas ou à incorporação 
de procedimentos técnicos que se pretendiam deduzidos a partir de explicações relativas à aprendizagem ou ao desenvolvimento.

Contudo, são poucos ainda, especificamente, os estudos históricos que buscam compreender como se deram essas práticas, por quais transformações passaram ao longo do tempo, utilizando que instrumentos e envoltos em quais rituais foram efetivamente realizadas as avaliações escolares. Sendo assim, vale reconhecer que "do ponto de vista de uma história 'do que a escola faz' esta pode ganhar muito em explicitação a partir da análise dos modos de examinar e avaliar os alunos” (CATANI, 2017, p. 9).

Alguns autores, no entanto, já têm assumido as práticas escolares de avaliação como objeto de pesquisa, ora centralmente, ora como parte de investigações que se debruçam sobre objetos relacionados. Por exemplo, Juarez José Tuchinski dos Anjos (2011), em Uma trama na história: a criança no processo de escolarização nas últimas décadas do período imperial (Lapa, Província do Paraná, 1866-1886), assumiu a perspectiva da microanálise para escrutinar as práticas de um professor paranaense, dentre as quais estavam os registros sobre os alunos, parte deles de avaliação. Carolina Ribeiro Cardoso da Silva (2014), em "O valor do aluno": vestígios de práticas de avaliação na escola primária (Florianópolis/SC, 1911 a 1963), empreendeu ampla análise documental, onde buscou indícios de práticas avaliativas que permitiam conhecer o aproveitamento escolar dos alunos e aspectos de ordem disciplinar. A mesma autora analisou, ainda, os saberes sobre avaliação presentes em livros para a formação de professores, em "A justa medida do progresso dos alunos": avaliação escolar em manuais de Pedagogia da segunda metade do século XIX (CARDOSO DA SILVA, 2018). Terciane Luchese (2014), no artigo Celebrações do saber: exames finais nas escolas da região colonial italiana, Rio Grande do Sul, 1875 a 1930, examinou legislação e atas de exames finais. Também Joseane Leonardi Craveiro El Hawat (2015) buscou descrever como se davam os exames escolares em Os saberes elementares matemáticos nas escolas isoladas de Porto Alegre: avaliações, programas de ensino e livros escolares (1873-1919). Fernanda Cristina Campos da Rocha (2017) dedicou-se a conhecer as formas de avaliar o aluno no estudo intitulado $A$ repetência e a reprovação na escola graduada, em Minas Gerais, nas primeiras décadas do século XX. Haveria, certamente, outras pesquisas a mencionar, mas mapear os trabalhos existentes foge do escopo deste artigo e extrapola os limites objetivamente colocados à sua escrita.

Em comum, os trabalhos que pretendem analisar as práticas de avaliação em perspectiva histórica têm as fontes documentais: a escrituração escolar e a legislação notadamente. Tais estudos se deparam com a dificuldade em conhecer as ações e as razões que as orientam. Nesse sentido, do ponto de vista historiográfico, a escrituração escolar - embora frequentemente lacunar - abre possibilidades preciosas antes imprevistas. Assim, fichas de registro de matrícula, boletins de notas, mapas de frequência, registros de inspeção, diários de classe, entre outros, são documentos que, quando disponíveis, trazem indícios acerca dos modos de fazer. Ou seja, importa reconhecer que

diversos suportes de escrita vão povoar a escola moderna e se diversificar com o passar dos séculos. Os vestígios documentais dessas práticas escriturísticas podem ser constituídos na pesquisa em História da Educação como fontes que nos permitem conhecer o trabalho docente, o alunado e algumas características dos percursos escolares, além de permitir compreender os modos de institucionalização da gestão escolar (GIL; HAWAT, 2015, p. 22). 
Na pesquisa aqui apresentada, a escrituração escolar é fonte principal - que pode, em outro momento, com a continuidade da pesquisa, vir a ser completada e confrontada com outras, tais como legislação e entrevistas. Nessa etapa, foram analisadas as fichas individuais de notas de alunos de uma escola católica de Porto Alegre. A descrição da documentação aparece mais adiante no texto, seguida da análise dos registros nela presentes, pretendendo não à apresentação de um a análise exaustiva, mas antes para servir como exemplo das potencialidades desse tipo de fonte.

\section{Avaliação escolar, classificação e excelência}

A avaliação escolar expressa um julgamento do aluno que tende a ter forte legitimidade social pelo próprio fato da escola ser considerada em nossa sociedade uma instituição capaz de identificar e desenvolver talentos supostamente inatos. Assim, segundo o pensamento moderno, à escola deveriam chegar todos os indivíduos de uma sociedade e nela seriam identificados aqueles mais aptos a prosseguir nos estudos e a assumir posições sociais mais destacadas. É nesse sentido que os liberais brasileiros defenderam, nas primeiras décadas republicanas, a importância de ampliar o acesso à escola democrática, ou seja, àquela escola que recebe todas as crianças, independentemente da origem social, e que se ocupa, por seus próprios meios, de selecionar as melhores (MANIFESTO..., 2010). É preciso se perguntar, então, quais são esses meios, como eles se constituíram historicamente e o que expressam sobre os alunos. Nesse sentido, considero produtivo estabelecer um diálogo inicial com pesquisas desenvolvidas na Sociologia da Educação para, em seguida, propor a análise propriamente histórica de fontes que nos permitem avançar a compreensão acerca dos significados socialmente atribuídos à avaliação escolar. Assim, parto da reflexão proposta por Philippe Perrenoud acerca da avaliação escolar, suas finalidades e seus processos de classificação. Perrenoud (1999, p. 9) afirma que

avaliar é - cedo ou tarde - criar hierarquias de excelência, em função das quais se decidirão a progressão no curso seguido, a seleção no início do secundário, a orientação para diversos tipos de estudos, a certificação antes da entrada no mercado de trabalho e, frequentemente, a contratação. Avaliar é também privilegiar um modo de estar em aula e no mundo, valorizar formas e normas de excelência, definir um aluno modelo, aplicado e dócil para uns, imaginativo e autônomo para outros.

Essas ações, tão tipicamente escolares, não tiveram desde o início da organização da escola moderna a centralidade que apresentam nos dias atuais. Embora a previsão dos exames constasse entre os elementos proposto para organização das primeiras escolas na Modernidade ${ }^{1}$, esse não foi por muito tempo um aspecto central no funcionamento do ensino. A avaliação escolar vai se institucionalizar aos poucos, na medida em que as próprias escolas vão assumindo forma e função mais definidas e mais institucionais. Perrenoud (1984, p. 106) ressalta, para o contexto europeu, que

o sistema de ensino não se orientou de início para a avaliação. [...] a avaliação formal desenvolveu-se apenas tardiamente; durante um longo período da história da escola, os mestres preocupavam-se, sobretudo, em ensinar. A necessidade de certificação das aquisições, tanto no interior do sistema escolar como para o mercado de trabalho, foi imposta somente a partir da configuração daquele sistema, inseparável de sua burocratização; ou em função da escolarização crescente das formações profissionais.

\footnotetext{
${ }^{1}$ A prescrição acerca dos exames aparece, no século XVII, tanto no Ratio Studiorum, que normatizava o ensino nas escolas jesuítas, quanto na Didática Magna, de Comenius, para as escolas protestantes.
} 
Quanto à preocupação de avaliar para melhor guiar a ação pedagógica, esta diz respeito a uma racionalidade didática recente.

Também no Brasil é possível observar que a avaliação escolar vai seguir processos muito fluidos, assistemáticos e, sobretudo, pouco eficazes por um longo tempo. No século XIX estão previstas em algumas legislações provinciais ${ }^{2}$ as visitas de inspeção e os exames finais, tendo ambos funções avaliativas. No entanto, os relatórios da instrução trazem durante todo o período reiteradas descrições do mau funcionamento do sistema, da insuficiência de inspetores, da falta de critérios comuns. É no século XX, envolto em um esforço mais ampliado de institucionalização da escola pública e democrática, com a instalação da escola seriada progressivamente em todos os estados da Federação e o detalhamento das regras de funcionamento dessa instituição, que a avaliação vai se afirmar como prática essencial da escola, sendo incentivada, prescrita em detalhes, e tendo ampliadas suas finalidades (SOUZA, 1998; ROCHA, 2008; CARDOSO DA SILVA, 2014).

A avaliação escolar adquire algumas funções específicas em sociedades onde a escolarização assumiu posição decisiva na regulação social, como é o caso das sociedades ocidentais na Modernidade. Avaliar serve para fundamentar decisões, relacionadas ao que se estabelece como êxito ou fracasso escolar e que engendra uma série de consequências (como a reprovação, a diplomação, a subjetivação dos alunos). A avaliação na escola introduz "um ponto de ruptura para criar conjuntos homogêneos; por um lado aqueles que serão reprovados [...] por outro, os que avançam no curso [...]" (PERRENOUD, 1999, p. 13, itálico original). Tem também a função de certificar aquisições em relação a terceiros, na medida em que os diplomas escolares são assumidos nos espaços não escolares como indicativos das capacidades e saberes adquiridos por seus portadores, embora forneçam efetivamente poucos detalhes acerca do nível de domínio precisamente atingido (PERRENOUD, 1999, p. 13).

No que se refere à dinâmica escolar propriamente, a avaliação tem grande importância. Perrenoud enfatiza que "em todos os casos, a avaliação não é um fim em si. É uma engrenagem no funcionamento didático e, mais globalmente, na seleção e na orientação escolares. Ela serve para controlar o trabalho dos alunos e, simultaneamente, para gerir os fluxos" (1999, p. 13, itálico acrescentado). As notas podem ser, portanto, meios disponíveis aos professores para controlar o trabalho e o comportamento de seus alunos, podem ser também recurso na regulação das relações pedagógicas e do contrato didático ${ }^{3}$, além de servirem como mensagem às famílias sobre os resultados e as consequências prováveis no transcurso do período escolar (PERRENOUD, 1999, p. 31-35).

As notas são, contudo, o aspecto mais visível da avaliação escolar, representam a codificação de um conjunto em geral bastante disperso e variado de processos avaliativos que se passam no cotidiano da escola. Embora se descreva frequentemente a nota como resultado de instrumentos objetivos de medição dos desempenhos na aprendizagem, tais meios e processos não tiveram sempre a mesma forma nem a mesma significação na escola e sua suposta objetividade precisa ser discutida. Segundo Perrenoud (1984, p. 137, itálico original), há na escola um processo de

avaliação informal, que se integra ao fluxo das interações cotidianas, ao qual não se dá muita atenção, que não é codificado, nem registrado, nem negociado. Isso não quer dizer que seja sem consequências, ao contrário. Julgando um aluno sobre certos aspectos de seu trabalho e de sua conduta em classe, o professor, independentemente de uma

\footnotetext{
${ }^{2}$ A título de exemplo, ver Jinzenji (2010), Anjos (2011) e Luchese (2014).

${ }^{3}$ Refiro-me aqui ao conceito proposto por Guy Brousseau na década de 1980. Segundo esse autor, o contrato didático corresponderia às regras estabelecidas entre professores e alunos no que se refere às atividades e comportamentos esperados de ambos em sala de aula.
} 
avaliação mais formal, constitui uma imagem relativamente estável de seu caráter e de suas competências. [...] a avaliação formal [por sua vez] fixa oficialmente o nível de excelência de cada aluno, seja em uma prova específica, seja em um período de trabalho, em uma disciplina definida ou, ainda, pelo conjunto do programa do ano escolar.

Dentre as dificuldades impostas ao pesquisador que se debruça sobre essa temática está o fato de que as práticas avaliativas são muito presentes no cotidiano escolar, mas raramente estão descritos os critérios e conteúdos efetivamente considerados. Na documentação que prescreve o funcionamento do ensino frequentemente aparece a menção à necessidade de estabelecer um momento de avaliação dos progressos dos alunos e, eventualmente, se indicam as escalas de pontuação, os tipos e momentos de avaliação que serão contabilizados para a nota ou conceito atribuído a cada aluno. No entanto, não costumam ser mencionados com precisão os conteúdos e as habilidades a serem avaliados em cada disciplina. Perrenoud (1999) destaca que tudo se passa como se a avaliação fosse uma decorrência óbvia e direta do que está colocado nos programas de ensino. Ocorre que todos nós sabemos que isso não transcorre assim. Entre a menção a um elemento a ser ensinado em dada matéria e aquilo que será efetivamente considerado na avaliação do aluno há um grande espaço a ser preenchido por cada professor.

Perrenoud sugere notar que uma parte significativa das apreciações acerca do desempenho dos alunos antecede e/ou passa longe dos momentos formais de avaliação. Assim, definem-se difusamente hierarquias de excelência escolar que aparecem, em maior ou menor medida, expressas em classificações fixas e comunicáveis. Segundo ele, "no decorrer do ano letivo, os trabalhos, as provas de rotina, as provas orais, a notação de trabalhos pessoais e de dossiês criam 'pequenas' hierarquias de excelência, sendo que nenhuma delas é decisiva, mas cuja adição e acúmulo prefiguram a hierarquia final” (PERRENOUD, 1999, p. 11, itálico original).

A norma de excelência considerada para a avaliação escolar é, ela própria, uma fabricação da escola. Os conhecimentos e a relação com o conhecimento que a escola apresenta como necessários na formação das novas gerações são, de fato, uma seleção arbitrária feita por grupos em posição de poder para definir os saberes legítimos (BOURDIEU; PASSERON, 1992). Os critérios e níveis de desempenho esperados dos alunos em cada etapa da escolarização são também definições arbitrárias. O êxito na escola não comunica efetivamente sobre as capacidades e saberes dos sujeitos examinados. Assim, na escola

o que se avalia não é o que se crê avaliar, porque se testam, por um lado, aquisições culturais e intelectuais muito gerais, independentes de um programa e de um ensino particular e, por outro, saberes estritamente contextualizados, dos quais frequentemente não resta grande coisa em uma situação um pouco diferente (PERRENOUD, 1999, p. 20).

A significação do êxito escolar é muito fortemente atrelada às regras especificamente escolares e ao conjunto arbitrário de saberes que esta instituição elegeu como relevantes. Ainda assim, os processos de avaliação e hierarquização escolar dos alunos são socialmente e subjetivamente percebidos como denotativos de capacidades e domínio de saberes avalizados. De modo geral,

ter êxito na escola, ser bom aluno é, na maioria das vezes, ser capaz de refazer em situação de avaliação, o que se exercitou longamente em situação de aprendizagem, diante de tarefas muito semelhantes e conforme instruções que sugerem, por sua própria forma, o que se deve procurar e que conhecimentos e operações mobilizar (PERRENOUD, 1999, p. 20). 
Nesse sentido, Perrenoud nos sugere pensar que, se as notas e conceitos atribuídos nas avaliações realizadas na escola dizem pouco efetivamente sobre os conhecimentos e as competências dos alunos, dizem bastante, contudo, acerca da posição de um aluno em relação aos outros na hierarquia de excelência escolar e da distância de cada um deles em relação à norma de excelência. Assim, importa notar que

as hierarquias de excelência e a posição de cada aluno nessas hierarquias resultam de uma fabricação relativamente complexa que, a partir do trabalho escolar cotidiano e dos desempenhos especialmente solicitados com vistas a avaliar os alunos, opera sínteses sucessivas de acordo com processos mais ou menos codificados (PERRENOUD, 1984, p. 15).

Segundo esse autor, é preciso compreender que

o êxito e o fracasso são realidades socialmente construídas, tanto em sua definição global quanto na atribuição de um valor a cada aluno, em diversas fases da trajetória escolar, através das práticas de avaliação que seguem, por um lado, procedimentos e escalas instituídas e, por outro, dependem, quanto ao restante, da arbitrariedade do professor e do estabelecimento (PERRENOUD, 1999, p. 19).

Conforme propõe Perrenoud, compreende-se aqui o êxito e o fracasso como representações. Ou seja, a avaliação escolar produz discursos sobre o desempenho dos alunos que servem como elementos de mediação das relações desses indivíduos com o mundo social, criam disposições, estabelecem traços distintivos e constroem os modos de ver. As representações podem ser entendidas como "atos de percepção e de apreciação, de conhecimento e de reconhecimento, em que os agentes investem seus interesses e pressupostos" (BOURDIEU, 1998, p. 107). Correspondem, assim, a "esquemas intelectuais incorporados que criam as figuras graças às quais o presente pode adquirir sentido, o outro tornar-se inteligível e o espaço ser decifrado" (CHARTIER, 2002, p. 17). Estas categorias, organizadas em classificações, divisões e delimitações que conformam as maneiras de perceber o mundo social, são disposições estáveis e partilhadas que, assim sendo, agem como mediadoras das práticas e discursos. Muito embora aspirem à universalidade, as representações são estruturas mentais relacionais determinadas pelos interesses e pelas posições sociais daqueles que as forjam.

Os resultados da avaliação, expressos em notas, não têm, portanto, a objetividade que a escola buscou advogar-lhes. Perrenoud (1984, p. 152, itálico original) lembra que

qualquer que seja a maneira dos professores darem notas, baseada num critério ou comparativa, rigorosa ou laxista, estável ou modulável, conduz diferentes professores a atribuir sentidos diferentes às mesmas notas, seja porque eles têm classes diferentes [...], seja porque eles não têm a mesma exigência absoluta [...]. A isto se juntam todas as variações qualitativas de interpretação e de especificação das normas de excelência.

Ocorre que, na primeira metade do século XX, no Brasil, as práticas escolares atuaram no sentido inverso dessa percepção, procurando um detalhamento cada vez maior da avaliação e de sua quantificação. O fracionamento da avaliação pelos vários conteúdos do ensino, a atribuição de notas por disciplina, o estabelecimento de períodos relativamente curtos (como o mês ou o bimestre) para a notação dos resultados escolares, são procedimentos que se afirmam nas escolas no período mencionado, pretendendo ampliar a objetividade e a qualidade da 
avaliação dos alunos. O escopo era a melhoria da aprendizagem e a maior eficiência do ensino, favorecendo o fluxo escolar da crescente população, infantil principalmente, que começava a chegar à escola. O resultado, no entanto, foi o aguçamento da seletividade e exclusão escolar, em processos de desqualificação dos sujeitos e com consequências objetivas na trajetória dos alunos. De qualquer modo, em que pese a relevância e a centralidade da avaliação na escola atual, a compreensão histórica dos processos pelos quais, ao longo do tempo, se expressaram e se registraram os desempenhos escolares é ainda escassa. Diante disso, considero produtivo, a título de exemplo, apresentar as análises dos livros de registros de notas de uma escola privada de Porto Alegre, entre 1957 e 1964. A partir desses documentos é possível perceber a minúcia na quantificação da avaliação operada pela escola no período. Antes, porém, importa fazer uma incursão pelas expectativas de objetividade na avaliação dos desempenhos dos alunos conforme expressas em documentação pedagógica entre os anos 1930 e 1960.

\section{Objetividade e impessoalidade: testes pedagógicos e a quantificação dos desempenhos}

A proposição de verificação e registro dos desempenhos dos alunos articula-se ao esforço observado na Modernidade para criar a escola e prescrever seu funcionamento. Carolina Ribeiro Cardoso da Silva (2018, p. 79) verifica, ao analisar manuais de pedagogia utilizados no Brasil no século XIX, que

o próprio termo avaliação ainda não fazia parte do léxico escolar e não aparece referenciado nos manuais, nem na legislação do ensino nesse período. Contudo, ao realizar a leitura das obras, percebeu-se que a avaliação - entendida como ato de atribuir valor a diferentes aspectos da vida escolar - era uma prática na escolarização do século XIX.

De acordo com a autora, os manuais evidenciam duas funções atribuídas ao ato de avaliar. A primeira delas estaria associada ao disciplinamento dos alunos, em mecanismos de controle da frequência, do comportamento e da aplicação. A segunda função seria classificatória, ou seja, importava mediante exames, provas e exercícios organizar os alunos em classes e também prover informações que indicassem a aprovação ou reprovação ao final do curso.

Embora os registros de atas de exames públicos realizados no século XIX no Brasil indiquem a predominância das menções descritivas dos desempenhos, em expressões tais como aprovado simplesmente, aprovado plenamente, aprovado com distinção ${ }^{4}$, Cardoso da Silva (2018) localiza nos manuais destinados à formação dos professores instruções para a atribuição de notas indicadas por números. Assim, por exemplo, no manual Curso Pratico de Pedagogia (publicado em 1851 na França; traduzido para o português e publicado no Brasil em 1865), Jean Baptiste Daligault mencionava como indispensáveis nas escolas três livros de registro: de inscrição ou matrícula; de chamadas e notas; de composição (CARDOSO DA SILVA, 2018). No livro de chamadas e notas deveriam ser registradas:

$1^{\circ}$. as faltas ou ausências dos discipulos, e seus motivos e $2^{\circ}$. as diversas notas, que elles tem merecido, tanto por sua conducta, e seu asseio, como pelo bom exito, ou bom sucesso obtido em cada um dos ramos do ensino, e bem assim os premios, ou pontos bons, que se lhes tem concedido em consequencia d’essas notas (DALIGAULT, 1870, p. 138, itálicos no original apud CARDOSO DA SILVA, 2018, p. 96).

\footnotetext{
${ }^{4}$ Alguns estudos já mencionados neste texto analisam a realização dos exames no século XIX. Ver, como exemplo, Jinzenji (2010), Anjos (2011) ou Luchese (2014).
} 
Para Daligault, as notas deveriam ser "tão exatas quanto possível" (CARDOSO DA SILVA, 2018) e, portanto, o autor prescrevia aos professores como proceder em relação a esse registro:

Todos os dias o Professor consigna em um canhoto ou memorial os factos mais importantes das lições, e que se referem ao trabalho, a conducta, e ao asseio dos alumnos. No fim da semana, sobre cada um d'esses objectos extrahe d'estas notas diarias uma nota hebdomadaria, ou semanal, que exprime por meio dos algarismos 5, 4, 3, 2, 1 (as quaes significão MUITO BEM, BEM, sufficientemente bem, mal, MUITO MAL) e as inscreve na columna do quadro á que a nota se refere (DALIGAULT, 1870, p. 139, itálicos no original apud CARDOSO DA SILVA, 2018, p. 101).

Cardoso da Silva (2018) detalha, ainda, que ao final de cada semana era preciso que os professores atribuíssem notas para cada ramo do ensino e, ao final do mês, essas notas deveriam ser somadas, calculando-se a média.

No início do século XX, a circulação do ideário escolanovista reafirmou e fortaleceu propostas de racionalização e padronização das práticas escolares, compreendidas como moderna pedagogia. Nesse sentido, a quantificação dos desempenhos escolares passou a se articular ao emergente entusiasmo com os testes psicológicos, cuja feição científica, deveria ampliar a eficiência do ensino (MONARCHA, 2009). Entre outros, a publicação, em 1930, do livro Introdução ao Estudo da Escola Nova, de Lourenço Filho (2002), fez circular amplamente os preceitos daquele movimento ao compilar as aulas de Psicologia e Pedagogia que o autor ministrava na Escola Normal de São Paulo. O autor apresentava as contribuições da psicologia experimental à educação, entre as quais os testes de inteligência e maturidade, ressaltando as vantagens do aspecto técnico que aportavam para a ação educativa. Na sua compreensão, tais elementos deveriam fazer parte da prática docente cotidiana:

Ao professor, em razão de suas funções específicas, que são as do trabalho na classe, não cabem obrigatoriamente as tarefas de psicologista escolar. Nem por isso, deverá ele desconhecer os modernos recursos da psicologia aplicada e, em particular, as bases gerais das aplicações de testes e escalas (LOURENÇO FILHO, 2002, p. 131).

Para Lourenço Filho (1947), a educação, como técnica, deveria valer-se da estatística como fundamento das medidas biológicas, psicológicas e educacionais no fazer educativo. Era preciso medir os alunos, permitindo um diagnóstico inicial e uma posterior verificação dos resultados do processo pedagógico, para se chegar a uma conclusão objetiva quanto à sua classificação. Para Loureço Filho (1947, p. 486, itálicos no original), a objetividade e impessoalidade na avaliação do rendimento escolar eram aspectos fundamentais para melhorar a eficiência da escola:

Pode-se estabelecer, com a aplicação de normas de verificação inicial e normas de verificação ulterior ao trabalho, um critério verdadeiramente técnico, quanto ao rendimento escolar. É essa consciência técnica, em particular, que a estatística vem trazer à intimidade do valor didático. Sem ela, o professor poderá ter uma atitude sentimental idealista, mesmo exaltada, em relação ao seu trabalho. Mas, com essa atitude já não nos satisfazemos mais em educação. O professor deve hoje também saber medir, saber verificar o seu próprio trabalho e o valor dos processos que emprega. 
Diante disso, afirmava que vinham se generalizando os sistemas de medidas objetivas do trabalho escolar e das capacidades dos alunos.

Não era, no entanto, questão nova a preocupação acerca das interferências sentimentais dos professores na aferição dos resultados do trabalho pedagógico e, em especial, nas notas atribuídas aos alunos em função de seus desempenhos escolares. Em 1937, por exemplo, Plínio Paulo Braga, em publicação periódica da Diretoria do Ensino de São Paulo ${ }^{5}$, apontava alguns problemas quanto aos critérios de promoção no ensino primário:

Não tem sido uniforme o criterio de promoções no curso primário. As notas variam de mestre para mestre e de momento para momento, por fundar-se o actual systema em critério pessoal e subjectivo, aggravado por influencias emotivas. [...] Estes processos, por assim dizer empiricos, mecanicos, poderão ser substituidos, com real vantagens, proveito e efficiencia para o ensino primario, pelo uso de testes, como meio mais rapido, scientifico e seguro de verificação do rendimento escolar (SECRETARIA DA EDUCAÇÃO E DA SAUDE PUBLICA, 1937, p. 29).

Outro exemplo pode ser observado em comunicado da Diretoria da Instrução Pública do Rio Grande do Sul, publicado em 1941 na Revista do Ensino:

Afim de organizar classes mais ou menos homogêneas e assim facilitar o trabalho do professor e aumentar o rendimento do trabalho escolar, a Secção Técnica [daquela Diretoria] estabeleceu, com base no resultado do tratamento estatístico a que foram submetidas as provas experimentais aplicadas no fim do último ano letivo, tabelas que deverão ser respeitadas, na distribuição dos alunos, pelas diferentes classes da escola primária (1941, p. 162).

A partir do resultado nessas provas, os alunos deveriam ser distribuídos em cinco diferentes classes, organizadas em função das diferenças de pontuação nas provas de matemática, estudos sociais e naturais e linguagem. O que se observa, portanto, é que para além dos testes psicológicos, buscou-se empregar nas escolas outros tipos de testes e provas que permitissem aferir de modo mais preciso e objetivo as aprendizagens realizadas.

Importa notar que está em debate no campo educacional, entre os anos 1930 e 1960, a importância da aferição objetiva dos desempenhos dos alunos e, nesse sentido, uma das alternativas postas em circulação foi o desenvolvimento de testes pedagógicos. A análise dos artigos publicados (entre 1944 e 1964) na Revista Brasileira de Estudos Pedagógicos, do INEP, sobre a avaliação escolar ${ }^{6}$ aponta o interesse recorrente quanto aos exames e diferentes tipos de testes. Para os colaboradores da revista, "o diagnóstico preciso do rendimento escolar e do aproveitamento dos alunos seria garantido pela objetividade dos exames", além disso, "o diagnóstico eficiente seria plausível em função do extraordinário desenvolvimento que havia ocorrido nos métodos quantitativos e qualitativos de avaliação" (KISTEMACHER, 2010, p.

\footnotetext{
${ }^{5}$ Foi realizada a análise acurada de todas as publicações oficiais da Diretoria de Ensino de São Paulo durante a década de 1930, buscando-se elementos acerca da questão em destaque neste artigo. Do mesmo modo, foram analisados os volumes da Revista de Ensino (Rio Grande do Sul) publicados entre 1939 e 1978 e os números da Revista Brasileira de Estudos Pedagógicos, publicada pelo INEP, entre os anos de 1944 e 1964. Os resultados obtidos indicam a convergência dos debates nos três conjuntos de publicação. Optou-se, em lugar de uma descrição minuciosa dos documentos examinados, focalizar aspectos centrais na argumentação aqui proposta trazendo apenas algumas citações a título de exemplo.

${ }^{6}$ Dilmar Kistemacher (2010) realizou análise da questão em sua Dissertação de Mestrado. Em seu trabalho é possível encontrar a síntese de alguns dos artigos publicados na Revista Brasileira de Estudos Pedagógicos.
} 
152). Lourenço Filho, por exemplo, ao defender a necessidade de objetividade nos exames escolares, permitindo torná-los instrumentos de medida dignos de confiança, menciona a preferência pelos testes pedagógicos, em lugar das provas escritas (LOURENÇO FILHO; HILDEBRAND, 1945). O autor detalha a proposta do seguinte modo:

As provas escritas, comumente aplicadas em nossas escolas, são de composição inteiramente arbitrária e de julgamento subjetivo. Isto é, de julgamento que se torna variável de mestre para mestre. O que se convencionou chamar de prova objetiva corresponde a material já selecionado com algum cuidado, enunciado de forma menos arbitrária, e suscetível, por isso, de avaliação menos precária. Testes pedagógicos ou de escolaridade, enfim, são provas compostas com material de antemão aferido, perfeitamente conhecido em seu teor de fidedignidade e de validade (LOURENÇO FILHO; HILDEBRAND, 1945, p. 53, itálicos no original).

No mesmo artigo, Armando Hildebrand (LOURENÇO FILHO; HILDEBRAND, 1945) também considera que as avaliações escolares precisavam ser revistas, no sentido de apresentarem maior objetividade. Segundo ele, os exames não eram necessários se continuassem "a ser provas, escritas ou orais, organizadas ao sabor do momento e corrigidas segundo o bom ou o mau humor dos mestres; se continua[ssem] a ser exposições decoradas de pontos sorteados, ou resposta a perguntas de algibeira" (LOURENÇO FILHO; HILDEBRAND, 1945, p. 51). Para Hildebrand, do modo como vinham sendo organizados, os exames estavam largamente baseados na sorte e não se configuravam como bons instrumentos de avaliação dos resultados reais da aprendizagem dos alunos. Assim, a racionalização das práticas escolares pressupunha, para o eficiente agrupamento dos alunos baseado em sua objetiva classificação, o recurso aos testes:

os testes mentais e os testes pedagógicos ou de escolaridade, aqueles para a verificação e medida das qualidades mentais estes para a verificação do aproveitamento do aluno nas diversas disciplinas. Aplicam-se ainda testes psicológicos, como elemento de orientação profissional, na verificação das tendências dos alunos, individual e coletivamente observados nas escolas primárias (JARDIM, 1946, p. 460).

A análise da imprensa pedagógica evidencia a crescente importância dada à exatidão, objetividade e impessoalidade nos processos de avaliação escolar. Pode-se, portanto, afirmar que nas instituições de formação de professores, ao longo da primeira metade do século XX, a atribuição de notas escolares expressas em números precisos foi considerada prática desejável que permitiria ampliar a eficiência do ensino. Tais discussões chegavam aos professores em exercício e devem ter impactado os modos pelos quais eles avaliavam seus alunos e registravam o aproveitamento das aulas. No entanto, entre a prescrição pedagógica, presente nos manuais e impressos destinados aos professores, e os instrumentos e práticas postos em funcionamento nas escolas existe uma distância que importa, pela pesquisa histórica, buscar averiguar. Nesse sentido, a análise de fichas de notas apresentada abaixo pode prover alguns indícios importantes e estimular novas pesquisas. 


\section{O desempenho dos alunos no curso primário da Escola Santa Clara (1957-1964)}

A Escola Santa Clara ${ }^{7}$ foi uma instituição de ensino que funcionou no município de Porto Alegre (RS) entre 1926 e 1983, mantida pela Sociedade Caritativa e Literária São Francisco de Assis. Oferecia inicialmente apenas o curso primário, em turmas femininas. Em 1962 começaram a funcionar as classes do ginásio. Nesse período, a escola recebia tanto meninas quanto meninos.

Para este estudo foram analisadas 531 fichas individuais onde estão registradas as notas dos alunos, referentes ao período de 1957 a 1963. Em 1964, as fichas estão reproduzidas em cadernos. Essa documentação foi localizada no arquivo do Setor de Controle Escolar da Secretaria de Educação e Cultura do Estado do Rio Grande do Sul (SEDUC/SECOE) que guarda, desde 1972, a documentação das escolas extintas de Porto Alegre. Além das fichas aqui consideradas, estão arquivadas nas caixas destinadas à documentação da Escola Santa Clara também atas de exame de admissão, relação nominal dos alunos matriculados, tabela de contribuição a ser cobrada dos alunos, relação do corpo docente, tabela de remuneração dos professores, lotação das turmas e área das aulas.

A escolha pela análise dessa documentação, selecionando o período de 1957 e 1964, deveuse à riqueza e raridade do corpus documental, um conjunto amplo, bastante completo, preenchido e bem preservado de fichas de notas de alunos. Trata-se de fichas individuais impressas, nos primeiros anos, e manuscritas ou mimeografadas em 1964. No cabeçalho das fichas estão o nome completo do aluno, sua idade, o ano letivo, a série cursada e a média geral. As fichas trazem na primeira coluna a relação das disciplinas do curso primário: comportamento, aplicação, religião, leitura, gramática, ditado, redação, aritmética, estudos sociais, desenho, trabalhos manuais, canto e educação física. Em seguida, há colunas para indicação das notas mês a mês, entre março e novembro. As últimas colunas são para registro da média das arguições mensais, da nota dos exames escrito e oral, da média final. Nas linhas de baixo, há espaço para indicar a média dos resultados a cada mês, assim como o lugar ocupado pelo aluno em relação aos colegas e as falhas, onde se devem indicar os totais de ausências às aulas.

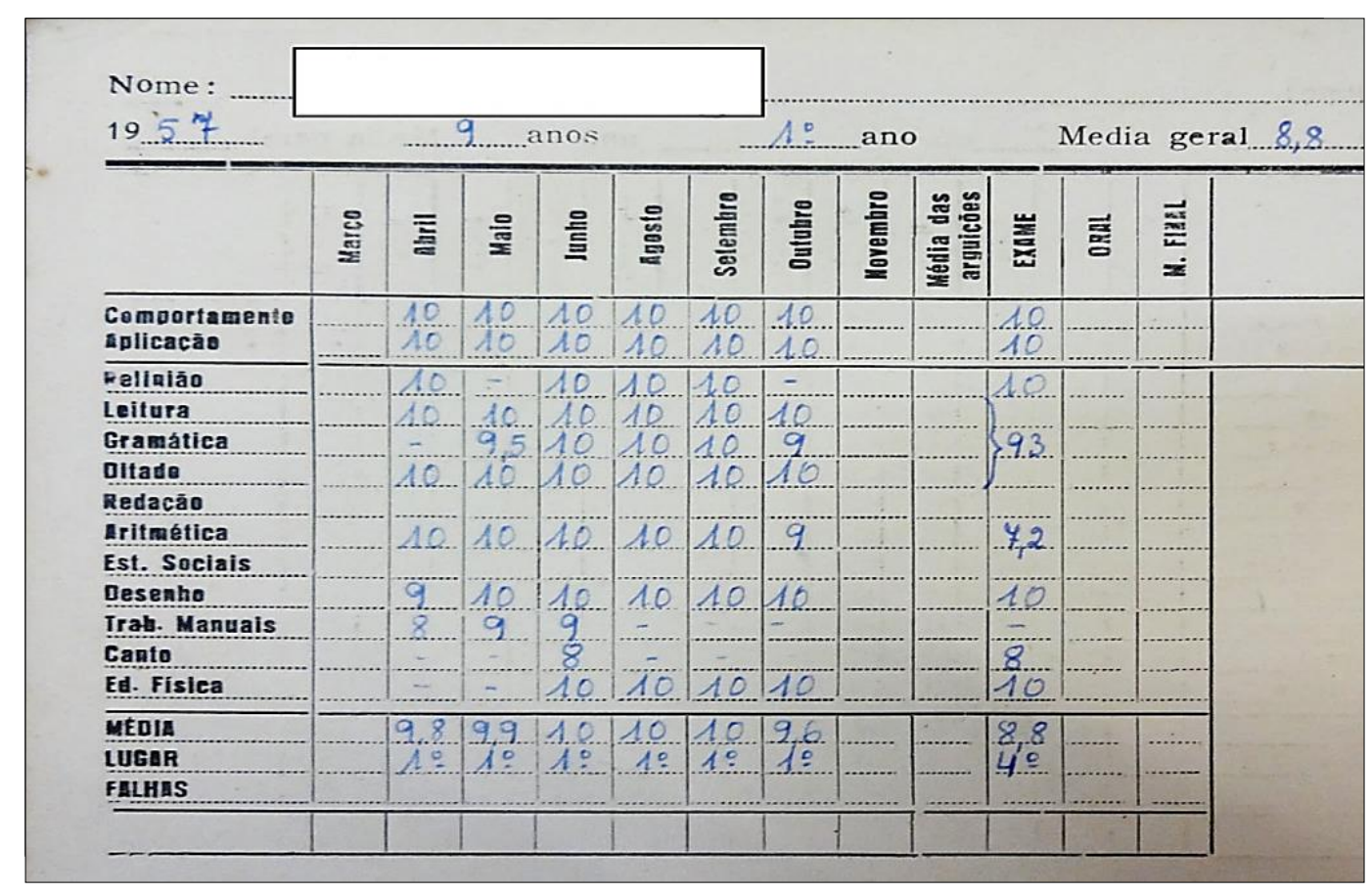

${ }^{7}$ Não foi possível localizar estudos prévios sobre a história dessa instituição. Assim, as informações sobre a escola apresentados neste artigo foram obtidos no mesmo arquivo em que estão depositadas as fichas de notas. 
Um primeiro aspecto que chama a atenção é o registro mensal das notas em cada disciplina, mesmo para as crianças menores, do $1^{\circ}$ e $2^{\circ}$ ano do curso primário, que tinham entre 6 e 9 anos. Outro elemento relevante é a previsão de que se registrem mensalmente a classificação dos alunos a partir da média das arguições nas disciplinas que contavam para a aprovação, explicitando enfaticamente as hierarquias de excelência. $\mathrm{O}$ mais comum no conjunto analisado é que haja uma variação na posição ocupada pelos alunos a cada mês, decorrente da diferença de desempenho de um mesmo aluno ao longo do ano.

Há uma diferença acentuada entre as fichas de 1957 e 1958 e as de 1964, no que diz respeito às notas. Embora as notas variem, às vezes bastante, de um mês a outro, em $1957 \mathrm{e}$ 1958, concentram-se marcadamente acima de 6,0 e são muito raras as notas abaixo de 5,0. Também se observa que os desempenhos baixos em aritmética são acompanhados de desempenhos igualmente baixos em português. Nesses anos, ainda, as notas para comportamento, aplicação, religião, desenho, trabalhos manuais, canto e educação física são expressas em números redondos (sem casas decimais) permitindo supor serem decorrentes de apreciações assumidamente mais subjetivas. Enquanto as demais, onde são frequentes as casas decimais, é possível que tenham sido obtidas em provas com pontuação definida para certo número de questões e exercícios. Em 1964, as notas abaixo de 5,0 são mais frequentes que nos anos anteriores, os desempenhos em aritmética, para alguns alunos, apresentam-se acentuadamente mais baixos do que nas outras disciplinas e a disciplina religião passa a receber notas fracionadas em decimais, como 8,2 por exemplo.

No que diz respeito à reprovação, cabe ressaltar que ela não é identificada nas fichas analisadas no início do período. Apenas em 1960 é que se tem o registro nas fichas, pela primeira vez, da reprovação de alunos. Analisando apenas as fichas da $1^{\text {a }}$ série é preciso mencionar que há o aumento do número de matrículas a cada ano, conforme se observa na tabela abaixo:

\begin{tabular}{|c|c|c|}
\hline Ano & Número matrículas $1^{\mathbf{0}}$ série & Reprovações \\
\hline 1957 & 14 alunos & - \\
\hline 1958 & 24 alunos & - \\
\hline 1959 & 38 alunos & 8 \\
\hline 1960 & 59 alunos & - \\
\hline 1961 & 51 alunos & 5 \\
\hline 1962 & 73 alunos & \\
\hline
\end{tabular}

Das 8 alunas reprovadas em 1960, apenas uma delas aparece matriculada na $1^{\mathrm{a}}$ série dessa escola em 1961 e segue a trajetória escolar sem novas retenções até, pelo menos, a $3^{\text {a }}$ série.

Como já se mencionou, são muitas as disciplinas que constam da ficha impressa. No entanto, nem todas são preenchidas. Assim, comportamento e aplicação recebem nota apenas nas turmas da $1^{a}$ série. Por outro lado, nessa série não aparecem registros em redação, estudos sociais e trabalhos manuais. Leitura, gramática e ditado compõem uma única média ao final do ano, no caso da $1^{\mathrm{a}}$ série, acrescidos de redação, para as demais séries do primário.

Nem todas as disciplinas que recebem nota ao longo do ano, no entanto, contam para o resultado final, ou seja, para a aprovação. Mesmo as médias mensais, que resultam na classificação expressa nas fichas, contabilizam apenas religião, português ${ }^{8}$, aritmética e estudos sociais. Interessa ressaltar, por exemplo, que as notas de comportamento e aplicação não entram no cálculo da média. O que não significa que não "contem", visto que certamente tinham peso na condução da relação cotidiana em sala de aula, favorecendo ou não, a apreciação nas situações formais de avaliação. Vale, ainda, destacar que são as disciplinas contabilizadas para a média final que recebem notas

\footnotetext{
${ }^{8}$ Nas fichas não aparece expresso dessa maneira, trata-se da média das notas de leitura, gramática, ditado e redação.
} 
com casas decimais (7,2 ou 8,9, por exemplo), o que faz pensar que, num esforço de objetivação, essas fossem avaliadas em situações mais formais e por instrumentos avaliativos que permitem a quantificação dos saberes, como provas e arguições. As demais, talvez por isso, pudessem ser avaliadas mais globalmente, a nota se expressando, muito mais frequentemente, em 9 ou 10. Religião tem, contudo, uma posição peculiar nesse sentido. Em 1957 e 1958 as notas dessa disciplina acompanham as de comportamento e aplicação, por exemplo, sendo expressas sem casas decimais e tendendo a 9 ou 10, embora façam parte do cálculo da média final. Corresponde, afinal, provavelmente ao único conteúdo cuja avaliação não compreende apenas o desempenho intelectual. Ilustrativo disso são as notas finais de uma aluna em 1957: português 5,3, aritmética 5,9, estudos sociais 5,2 e religião 8,6 . Ou seja, religião contrastava com as demais notas e contribuiu para aumentar a média final da aluna, que fechou em 6.

Um último aspecto que merece ser destacado na análise das fichas, diz respeito à evidência de algumas permanências nos modos de atribuir notas. Em 1964, a escola já não utiliza mais a ficha impressa dos primeiros anos, mas continua registrando as notas em fichas individuais mimeografadas ou reproduzidas a mão em um caderno. As fichas mimeografadas são muito mais simples que as anteriores. Delas não constam os itens comportamento e aplicação e tampouco trazem espaço para registrar o lugar de cada aluno na hierarquia das notas. O que chama a atenção é que, como a escola passa a ter duas turmas para cada série, o preenchimento difere, fazendo refletir sobre aquilo que era obrigatório constar das fichas e o que era considerado relevante pelas professoras. Assim, por exemplo, nas fichas do $1^{\mathrm{o}}$ ano A, de 1964, o campo lugar só aparece preenchido para os 10 melhores colocados a cada mês. Na turma do $1^{\circ}$ ano $\mathrm{B}$, naquele mesmo ano, este campo não está nunca preenchido, mesmo que as notas de vários alunos sejam bastante altas.

A comparação das fichas do $2^{\circ}$ ano $\mathrm{A}$ e $\mathrm{B}$, produzidas à caneta em um caderno, evidencia as escolhas dos professores na própria composição da ficha. Assim, para a turma A aparece a categoria atitude onde estão registrados OT, MB e REG (ótimo, muito bom e regular). Isso indica a permanência da apreciação dos comportamentos que antes recebiam notas quantificadas nas fichas de comportamento e aplicação. A ausência dessas categorias na ficha mimeografada já indicava que não eram mais conteúdos cuja avaliação devia ser formalizada nos registros. Essa mesma professora inclui nas fichas um campo para as notas de bordado, apenas para as meninas. A professora da turma B, compõe sua ficha de modo diferente. Reproduz ficha antiga, impressa, apenas excluindo comportamento e aplicação, sem incluir nenhuma outra categoria. Também não aparece bordado, mas há notas para trabalhos manuais apenas nas fichas das meninas.

\section{Considerações Finais}

Neste artigo procurei trazer considerações teórico-metodológicas e alguns resultados oriundos de pesquisa histórica documental sobre a avaliação dos desempenhos escolares de alunos do ensino primário. Parti da compreensão de que o tema da avaliação escolar configurase como muito relevante e bastante atual. Desse modo, ampliar a compreensão da história dos processos de avaliação escolar permite fortalecer e diversificar os estudos em História da Educação, bem como aportar elementos importantes e pouco presentes no debate atual sobre a questão: tais como a ilusão de objetividade da quantificação dos desempenhos e a contradição da escola democrática que persiste em práticas avaliativas seletivas e excludentes.

A atribuição de notas é o foco privilegiado das análises aqui apresentadas, aspecto sobre o qual temos ainda poucos estudos no campo. A intenção foi trazer, em diálogo com estudos sociológicos e históricos, um exame inicial da documentação. Dos resultados, o que mais se destaca é o detalhamento e a precisão dos registros quantitativos que pretendem indicar os 
desempenhos dos alunos. Assim, é expressivo da racionalidade classificatória que orienta as ações e os sujeitos da escola que as notas sejam atribuídas a cada um dos conteúdos

escolares mês a mês e que as médias mensais permitam posicionar os alunos numa ordem aferida pelos valores obtidos. Integra igualmente essa razão prática, a frequência com que as notas são expressas por valores fracionados em decimais, tais como 8,2 ou 6,9. Por fim, cabe mencionar que categorias como comportamento e aplicação compõem o rol das categorias nas quais os alunos são avaliados e recebem, assim como nas demais, notas.

\section{Referências}

ANJOS, Juarez José Tuchinski dos. Uma trama na história: a criança no processo de escolarização nas últimas décadas do período imperial (Lapa, Província do Paraná, 1866-1886). UFPR, 2011. Dissertação (Mestrado em Educação) - Faculdade de Educação, Universidade Federal do Paraná, Curitiba, 2011.

BOURDIEU, Pierre; PASSERON, Jean Claude. A reprodução. Rio de Janeiro: Francisco Alvez, 1992.

BOURDIEU, Pierre. A força da representação. A economia das trocas lingüísticas: o que falar quer dizer. $2^{a}$ ed. São Paulo: Edusp, 1998, p.107-116.

CAMBI, Franco. História da Pedagogia. São Paulo: Editora UNESP, 1999.

CARDOSO DA SILVA, Carolina Ribeiro. "O valor do aluno": vestígios de práticas de avaliação na escola primária (Florianópolis/SC, 1911-1963). UDESC, 2014. Dissertação (Mestrado em Educação). Universidade do Estado de Santa Catarina, Florianópolis, 2014.

CARDOSO DA SILVA, Carolina Ribeiro. "A justa medida do progresso dos alunos": avaliação escolar em manuais de pedagogia (segunda metade do século XIX). UDESC, 2018. Tese (Doutorado em Educação). Universidade do Estado de Santa Catarina, 2018.

CARDOSO DA SILVA, Carolina Ribeiro; GASPAR DA SILVA, Vera Lucia. O aluno sob medida: como a escola registra seus alunos? Caderno de História da Educação, Uberlândia, v. 14, n. 1, jan./abr., 2015.

CATANI, Denice Barbara. História das práticas de avaliação no Brasil: provas, exames e testes ou a longa provação dos alunos rumo à distinção ou ao "triunfo escolar" (1890-1960). Currículo sem Fronteiras, v. 17, n. 1, p. 8-14, 2017.

CHARTIER, Roger. A história cultural: entre práticas e representações. 2ª ed, Lisboa: Difel, 2002.

DAligault, Jean Baptiste. Curso Pratico de Pedagogia. Desterro: Typografia Ribeiro \& Caminha, 2. ed., 1870.

FOUCAULT, Michel. Vigiar e Punir. 10a ed. Petrópolis: Vozes, 1987.

GATTI, Bernadete A. Avaliação educacional no Brasil: pontuando uma história de ações. Eccos, v. 4, n. 1, p. 17-41, 2002. https://doi.org/10.5585/eccos.v4i1.291

GIL, Natália de Lacerda; HAWAT, Joseane El. O tempo, a idade e a permanência na escola: um estudo a partir dos livros de matrícula (Rio Grande do Sul, 1895-1919). História da Educação, Porto Alegre, v. 19, n. 46, p. 19-40, 2015. https://doi.org/10.1590/2236-3459/50877 
HAWAT, Joseane Leonardi Craveiro El. Os saberes elementares matemáticos nas escolas isoladas de Porto Alegre: avaliações, programas de ensino e livros escolares (1873-1919). UFRGS, 2015. Dissertação (Mestrado em Educação). Universidade Federal do Rio Grande do Sul, Porto Alegre, 2015.

JARDIM, Germano. A coleta da estatística educacional (IV). Revista Brasileira de Estudos Pedagógicos, v. 7, n. 21, p. 452-463, março-abril, 1946.

JINZENJI, Mônica Yumi. As escolas públicas de primeiras letras de meninas: das normas às práticas. Revista Brasileira de História da Educação, São Paulo, n. 22, p. 169-198, jan.-abr. 2010.

KISTEMACHER, Dilmar. Avaliação e qualidade da educação na Revista Brasileira de Estudos Pedagógicos/INEP (1944-1964). UNISINOS, 2010. Dissertação (Mestrado em Educação). Universidade do Vale do Rio dos Sinos, São Leopoldo, 2010.

LOURENÇO FILHO. Estatística e educação. Revista Brasileira de Estudos Pedagógico, v. XI, n. 31, p. 467-488, nov.-dez., 1947.

LOURENÇO FILHO. Introdução ao Estudo da Escola Nova. 14. ed. Rio de Janeiro: EdUERJ/Conselho Federal de Psicologia, 2002.

LOURENÇO FILHO; HILDEBRAND, Armando. São necessários os exames escolares?. Revista Brasileira de Estudos Pedagógicos, v. 4, n. 10, p. 51-54, abril 1945.

LUCHESE, Terciane Angela. Celebrações do saber: exames finais nas escolas da região colonial italiana, Rio Grande do Sul, 1975 a 1930. Revista Diálogo Educacional, Curitiba, v. 14, n. 41, jan./abr., 2014. https://doi.org/10.7213/dialogo.educ.14.041.AO03

LUCKESI, Cipriano Carlos. Avaliação da aprendizagem na escola e a questão das representações sociais. Eccos, v. 4, n. 2, p. 79-88, 2002. https://doi.org/10.5585/eccos.v4i2.310

MANIFESTO dos Pioneiros da Educação Nova (1932) e dos educadores 1959. Recife: Fundação Joaquim Nabuco, Editora Massangana, 2010.

MERCIER, Pascal. Trem noturno para Lisboa. 10. ed. Rio de Janeiro: Record, 2013.

MONARCHA, Carlos. Brasil arcaico, Escola Nova: ciência, técnica e utopia nos anos 1920 1930. São Paulo: Ed. UNESP, 2009.

"ORIENTAÇÃO pedagógica". Comunicado da Diretoria de Instrução Pública. Secção técnica. Revista do Ensino, Porto Alegre, v. 5, n. 17-18, p. 162-163, jan.-fev., 1941.

PERRENOUD, Philippe. La fabrication de l'excellence scolaire: du curriculum aux pratiques d'évaluation. Genebra: Librairie Droz S.A., 1984.

PERRENOUD, Philippe. Avaliação: da excelência à regulação das aprendizagens - entre duas lógicas. Porto Alegre: Artmed, 1999.

ROCHA, Fernanda Cristina Campos da. A Reforma João Pinheiro nas práticas escolares do Grupo Escolar Paula Rocha/Sabará (1907-1916). UFMG, 2008. Dissertação (Mestrado em Educação). Universidade Federal de Minas Gerais, Belo Horizonte, 2008. 
ROCHA, Fernanda Cristina Campos da. A repetência e a reprovação na escola graduada, em Minas Gerais, nas primeiras décadas do século XX. UFMG, 2017. Tese (Doutorado em Educação). Universidade Federal de Minas Gerais, Belo Horizonte, 2017.

SECRETARIA DA EDUCAÇÃO E DA SAÚDE PÚBLICA. Directoria do Ensino. As reuniões pedagogicas de janeiro de 1937. São Paulo, 1937. [Boletim n. 13]

SOUZA, Rosa Fátima de. Templos de Civilização: a implantação da escola primária graduada no Estado de São Paulo (1890-1910). São Paulo: UNESP, 1998. 